\title{
Percepção de Homens e Mulheres Acerca de Quem Entrega um Filho para Adoção
}

Resumo:Este trabalho tem como objetivo investigar como os indivíduos percebem a pessoa que entrega um filho para adoção e as circunstâncias que envolvem este ato. Para tal, foram entrevistados 10 adultos e, após a categorização das respostas por temas afins, foi montado um questionário que foi aplicado a 60 pessoas de diferentes idades e profissões, sendo 30 de cada sexo. As variáveis analisadas foram as seguintes: características de quem doa um filho, motivos que levam à doação, pontos positivos na doação de um filho, repercussões da doação na vida de quem doa e na vida da criança, justificativas para a doação de um filho e direito ao reencontro entre doador e o filho. Concluímos por uma maior abertura para com o tema, embora ainda permeado de contradições e ambivalências, tendo as mulheres se mostrado um pouco mais severas na percepção sobre os doadores e sobre a possibilidade do reencontro com o filho. Os homens, por sua vez, destacaram-se ao assinalar que a doação se dá por falta de preocupação com o filho, sendo tal resultado significativo.

Palavras-Chave: Doação/entrega, pais que doam, adoção.

\section{Ivana Suely Paiva Bezerra de Mello}

Professora de Psicologia do UNIPÊ. Pessoa, mestre em Psicologia Clínica.

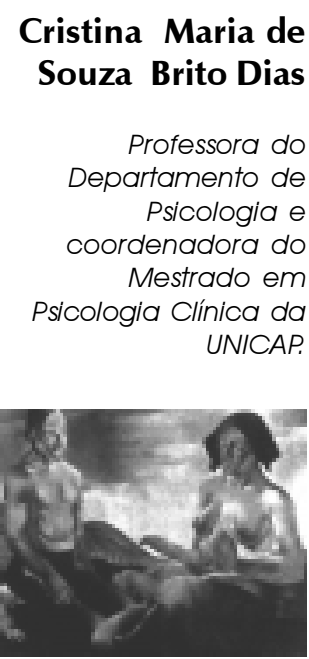

Abstract:The objective of the present paper is to investigate how people see the attitude of those who give away his/her child for adoption and what circumstances this action involves. In order to do that 10 adults were interviewed and their answers classified by similar themes. So, we made up a questionnaire containing these themes which were applied to 60 (30 males and 30 females) people of different ages and professions. The following variables were analyzed: the personal characteristics of the parents, their motivations, the positives aspects of this donation, the consequences of this act in the life of the one who made the donation and also in the child's life himself, the justification for the donation of a child and the right of a future meeting between the parents and the child. Although many ambivalences and contradictions were found, we concluded by a wider view of this problem. Specifically we observed that women tend to be more severe in their perception about the donors and the possibility of future meeting. On the other hand, men significantly pointed out that the donation takes place due to the lack of concern with a child.

Key Words: Donation/delivery, parents who donate, adoption.

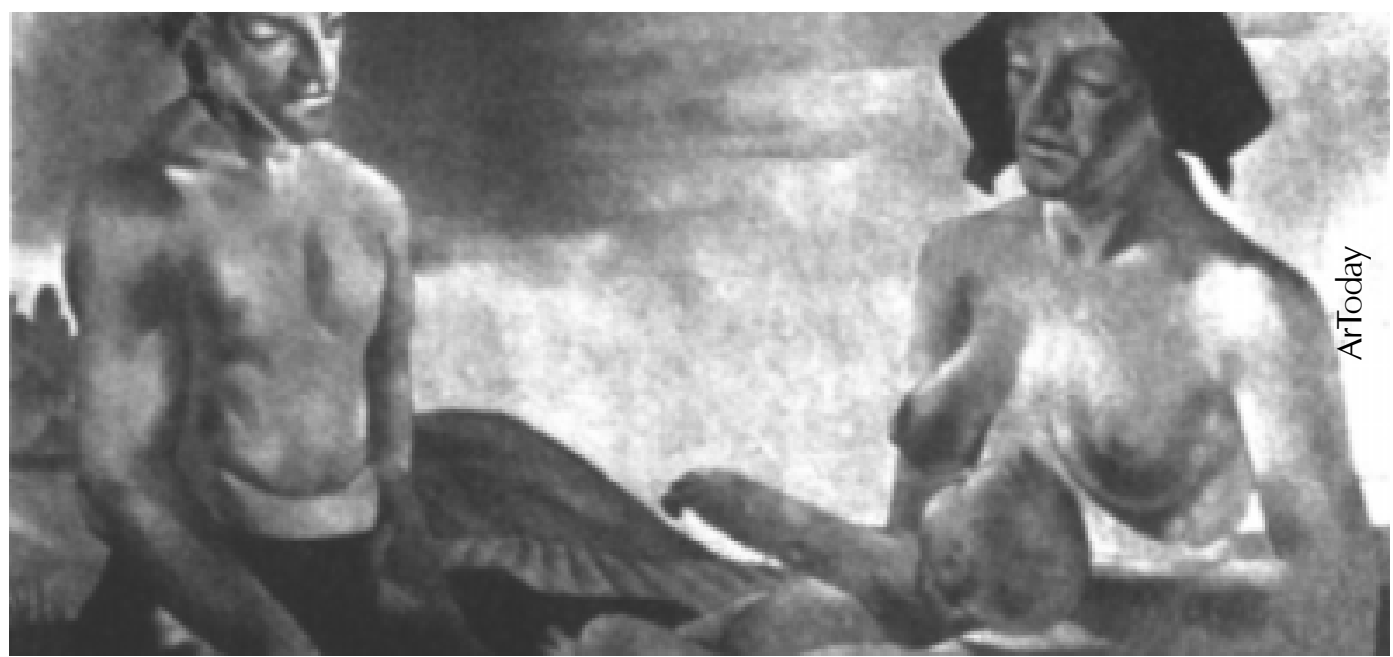

Temos constatado um aumento da literatura existente sobre adoção, bem como de grupos de estudo e apoio à adoção em todo o Brasil. No entanto, existem ainda poucos estudos no que se refere à outra face da adoção, que é a entrega ou doação de um(a) filho(a) para adoção. Esta entrega geralmente é feita pela mãe, sendo o pai omitido nesse processo, uma vez que se acredita que, algumas vezes, ele nem sabe da gravidez ou então abandona a companheira e o filho. Sabe-se menos ainda sobre os pais biológicos de crianças adotadas. 
Alguns trabalhos que se detiveram na mãe doadora tendem a vê-la, geralmente, como uma pessoa excluída, estigmatizada, de má conduta, delinqüente e de comportamento sexual indesejável (Hartman, 1994). Os próprios profissionais que lidam com essas mães não as escutam ou tendem a classificá-las segundo estes estereótipos, que os protegem de uma escuta mais espontânea para compreenderem o que de fato as está levando àquele ato (Giberti, Gore e Taborda 2001). As autoras salientam que "a cegueira social que omite a existência das mães doadoras como pessoas as enquadra na posição de provedoras de filhos para outros" (p. 178). Dessa forma, não é questionado seu papel, como se tivesse que se continuar assim. Freston e Freston (1994) realizaram um trabalho sobre a doação de recém-nascidos atendidos na enfermaria de Obstetrícia e Neonatalogia do Centro de Atenção Integral à Saúde da Mulher, da Universidade Estadual de Campinas, tendo examinado os fatores que contribuem para a decisão materna de doar um filho. O perfil que emergiu da mãe doadora corresponde ao de uma mãe solteira ou sem companheiro no momento do parto, com idade acima de 21 anos, com educação primária incompleta, trabalho incerto como empregada doméstica, sem outras fontes de renda e que engravidou de relação eventual.

Giberti et col. (2001) também encontraram que as mães doadoras são mulheres que pertencem ao setor mais desfavorecido, com baixos salários e necessidades básicas insatisfeitas, além de serem jovens e migrantes.

O trabalho de Bonnet (1991) trouxe uma outra visão sobre aquilo que a nossa sociedade chama de abandono ao afirmar que a ruptura da filiação é um ato de amor para proteger a criança. Segundo a autora, se as mães decidiram se separar definitivamente de seus bebês desde o seu nascimento, o fazem para protegê-los da violência que as habita. Assim, isto é considerado um ato de amor, pois as mães se identificam com as necessidades da criança. $O$ amor que elas não tiveram nas suas vidas não poderão dar, então renunciam aos filhos para que sejam cuidados por outros. Gonzales e Albornoz (1990) também admitem que a doação se dá por ser a única saída de proteger o filho do desamparo vivido por elas, as mães. Dessa forma, através da doação, é permitida à criança uma chance de existência. Leão (1990) comenta que o melhor para o sujeito é que ele encontre alguém que o deseje, acreditando que a normalidade da pessoa é determinada pelos desejos, e, principalmente, pela qualidade desses desejos, pois isso fará com que a criança possa ter um desenvolvimento adequado em direção à independência e à autonomia.

Santos (2001), por sua vez, embora admitindo que os fatores de ordem sócio-econômica são importantes para justificar a entrega de um filho para adoção, salienta que, por si sós, eles não são suficientes. Na sua experiência de lidar há vários anos com as mães doadoras, a autora constata que nem todas são pobres e excluídas, como também nem todas sofrem a dor da perda e da impossibilidade de maternar os filhos. Isso pode ser observado, inclusive, através da História. A autora supõe que existam motivações interiores, subjetivas, que levam essas mulheres à doação e chama a atenção para que se evite uma leitura moralizadora ou ideologicamente tendenciosa acerca dessa questão, sendo importante que os profissionais que lidam com essas pessoas adotem uma postura de respeito e convivência com as diferenças culturais, ideológicas e individuais dos grupos atendidos.

Tendo descortinado um pouco a complexidade que envolve o tema doação/entrega de um filho para adoção, interessamo-nos em realizar uma pesquisa com o objetivo de investigar como homens e mulheres, com vários níveis de escolaridade e profissão, percebem a pessoa do doador e as circunstâncias que envolvem o ato de entregar um filho para adoção.

\section{Metodologia}

\section{Sujeitos}

Inicialmente, foi realizada uma entrevista semiestruturada com 10 pessoas de ambos os sexos. Após a categorização das respostas por temas afins, foi montado um questionário contendo 7 questões fechadas e de múltipla escolha. O questionário foi aplicado a 60 pessoas, 30 de cada sexo, com idades variando entre 21 a 77 anos. Todos os sujeitos tinham filhos e residiam na cidade de João Pessoa.

\section{Instrumento}

O questionário utilizado compreendeu os dados sócio-demográficos e as questões pesquisadas que correspondem às seguintes dimensões: características de quem doa um filho, motivos que levam à doação de um filho, pontos positivos na doação de um filho, repercussões da doação na vida de quem doa, repercussões da doação na vida do filho, justificativas para a doação e direito de o doador reencontrar seu filho.

\section{Procedimento}

Os sujeitos foram procurados em ambientes de trabalho, bem como na universidade, tendo-lhes sido explicado o objetivo da pesquisa e solicitada sua colaboração.

\section{Resultados}

Os dados da pesquisa foram tratados em termos de freqüência e percentual, como também foi realizado 
o Qui-quadrado $\left(X^{2}\right)$ para observar se havia diferenças entre os sexos. Vale salientar que, por ser um questionário de múltipla escolha, o percentual em cada variável pode ultrapassar $100 \%$. Denominamos os sujeitos do grupo masculino G. Masc. e os do grupo feminino, G. Fem.

A tabela 1 apresenta os resultados referentes às características percebidas na pessoa que entrega um filho para adoção.

Tabela 1 - Freqüência e percentual das características da pessoa que doa um filho, na percepção dos sujeitos $(\mathrm{N}=60)$.

\begin{tabular}{l|l|l|}
\hline Características de quem doa um filho & G. Masc. & G. Fem. \\
$\begin{array}{l}\text { Incapaz de criar um filho devido à situação } \\
\text { financeira }\end{array}$ & (16) $53 \%$ & (18) $60 \%$ \\
\hline Irresponsável & (10) $33 \%$ & (8) $27 \%$ \\
\hline Imatura & (7) $23 \%$ & (7) $23 \%$
\end{tabular}

Como podemos observar na tabela acima, o item incapaz de criar um filho devido à situação financeira aparece em primeiro lugar, tanto nos homens (53\%) como nas mulheres (60\%). Já 33\% dos homens e $27 \%$ das mulheres consideram-na irresponsável. O item imatura ficou com 23\% para ambos os sexos como característica da mãe que doa.

Na tabela 2 encontramos os motivos que levam uma mãe a doar um filho, na percepção dos sujeitos.

Tabela 2 - Freqüência e percentual dos motivos que levam uma pessoa a doar um filho $(N=60)$.

\begin{tabular}{|c|c|c|c|}
\hline Motivos que levam à doação de um filho & G. Masc. & G. Fem. & $x^{2}$ \\
\hline Achar que outra pessoa cuidará melhor do seu filho & (17) $57 \%$ & (17) $57 \%$ & \\
\hline Falta de preocupação com o filho & (16) $53 \%$ & (5) $17 \%$ & $5,67^{*}$ \\
\hline Falta de condições financeiras & ----------- & (17) $57 \%$ & \\
\hline Imaturidade & (6) $20 \%$ & (10) $33 \%$ & \\
\hline Excesso de egoísmo & ------------ & (6) $20 \%$ & \\
\hline Ignorância & (5) $17 \%$ & (5) $17 \%$ & \\
\hline
\end{tabular}

${ }^{*} p<0,05$

Tanto os homens como as mulheres, num percentual de 57\%, consideram que o principal motivo para essa atitude é acreditar que outra pessoa cuidará melhor de seu filho. Este foi seguido da por falta de preocupação com o filho para 53\% dos homens, enquanto que, entre as mulheres encontramos $17 \%$ com essa percepção. Esse resultado foi significativo a favor do grupo masculino $\left(X^{2}=5,67 p<0,05\right)$ e chamou-nos a atenção, já que os mesmos homens, num percentual de $57 \%$, afirmam que a doação se daria devido ao fato de o doador considerar que outra pessoa cuidaria melhor de seu filho. A falta de condições financeiras apareceu para 57\% das mulheres como fator relevante para esse ato, sendo que nesse item os homens se abstiveram. A imaturidade ainda se apresenta como um dado importante para ocorrer a doação $(20 \%$ para os homens e $33 \%$ para as mulheres). Excesso de egoísmo apareceu em 20\% nas mulheres, sendo ausente no grupo masculino. Finalmente, a ignorância foi apontada por $16 \%$ dos homens e $17 \%$ das mulheres.

A tabela 3 apresenta os resultados acerca dos pontos positivos na doação de um filho.

Tabela 3 - Freqüência e percentagem dos pontos positivos na doação de um filho ( $N=60$ ).

\begin{tabular}{|l|r|c|}
\hline Pontos positivos na doação de um filho & G. Masc. & G. Fem. \\
\hline $\begin{array}{l}\text { É a continuidade de uma vida } \\
\text { Oferecimento de condições de sobrevivência }\end{array}$ & (14) $47 \%$ & (11) $37 \%$ \\
\hline e cuidados mais adequados à criança & (12) $40 \%$ & (16) $53 \%$ \\
\hline Não foi praticado um aborto & (6) $20 \%$ & (9) $30 \%$ \\
\hline Faz outra(s) pessoa(s) feliz(es) & (5) $17 \%$ & (8) $27 \%$ \\
\hline
\end{tabular}


De acordo com a tabela 3, podemos constatar que $47 \%$ dos homens e $37 \%$ das mulheres consideram como ponto positivo na doação de um filho a continuidade de uma vida, ficando em segundo lugar o oferecimento de condições de sobrevivência e cuidados mais adequados à criança (40\% para os homens e 53\% para as mulheres). Ainda encontramos como pontos positivos não foi praticado um aborto para $20 \%$ dos homens e $30 \%$ das mulheres, e faz outras pessoas felizes para $17 \%$ dos homens e $27 \%$ das mulheres.

Na tabela 4, estão dispostos os resultados acerca das repercussões da doação na vida da pessoa que doa um filho.

\begin{tabular}{|c|c|c|}
\hline Repercussões da doação na vida de quem doa & G. Masc. & G. Fem. \\
\hline Sentimentos de perda/vazio & (11) $37 \%$ & (14) $47 \%$ \\
\hline Preocupação com o futuro do filho & (10) $33 \%$ & (7) $23 \%$ \\
\hline Culpa e remorso & (6) $20 \%$ & (14) $47 \%$ \\
\hline Desespero e amargura & (5) $17 \%$ & (9) $30 \%$ \\
\hline Alívio por se livrar da responsabilidade & ---------- & (7) $23 \%$ \\
\hline Arrependimento & (6) $20 \%$ & (6) $20 \%$ \\
\hline Dúvida sobre seu ato & (6) $20 \%$ & (6) $20 \%$ \\
\hline
\end{tabular}

Como podemos visualizar na tabela 4, foram encontradas as seguintes percepções: $37 \%$ dos homens e $47 \%$ das mulheres acreditam que a repercussão na vida de quem doa é um sentimento de perda e de vazio, seguido de preocupação com o futuro do filho; assim encontramos $33 \%$ dos homens e $23 \%$ das mulheres pensando dessa forma. Já o item culpa e remorso foi detectado em $47 \%$ das mulheres, e desespero e amargura em 30\% das mesmas. Já nos homens, podemos observar que, depois dos sentimentos de perda e vazio, 37\%, viria a preocupação com o futuro do filho, 33\%, sentimentos de culpa e remorso (20\%) e desespero e amargura aparecem com percentagem menor (17\%). Nos itens arrependimento e dúvida sobre seu ato, encontramos percepções semelhantes, ou seja, $20 \%$ para ambos os sexos. Chama a atenção que o item alívio por se livrar da responsabilidade só foi assinalado pelas mulheres (23\%).

A tabela 5 apresenta os resultados das repercussões da doação na vida do filho.

\begin{tabular}{|l|l|l|}
\hline Tabela 5 - Freqüência e percentagem das repercussões da doação na vida do filho (N=60). \\
\begin{tabular}{l|l|l|}
\hline Repercussões da doação na vida do filho & G. Masc. & G. Fem \\
\hline Depende da idade em que a criança for adotada & $(20) 67 \%$ & (14) $47 \%$ \\
Sentimentos de vazio/rejeição & $(11) 37 \%$ & (10) $33 \%$ \\
\hline Desajuste emocional & (4) $13 \%$ & (10) $33 \%$ \\
Tristeza/baixa auto-estima & (2) $7 \%$ & (5) $17 \%$ \\
Impossibilidade de ser um indivíduo ajustado e feliz & (2) $7 \%$ & (1) $3 \%$
\end{tabular} \\
\hline
\end{tabular}

Quanto às repercussões da doação na vida do filho, encontramos, em primeiro lugar, que elas dependem da idade em que a criança foi adotada (67\% para os homens e $47 \%$ para as mulheres), seguida de sentimentos de vazio e rejeição (37\% para os homens e $33 \%$ para as mulheres), desajuste emocional, (13\% para os homens e $33 \%$ para as mulheres), tristeza/baixa auto-estima (7\% para homens e $17 \%$ para mulheres), e impossibilidade de ser feliz, com uma percentagem bem baixa, $7 \%$ para homens e $3 \%$ para mulheres.

Na tabela 6, encontramos os resultados acerca das justificativas para a doação de um filho.

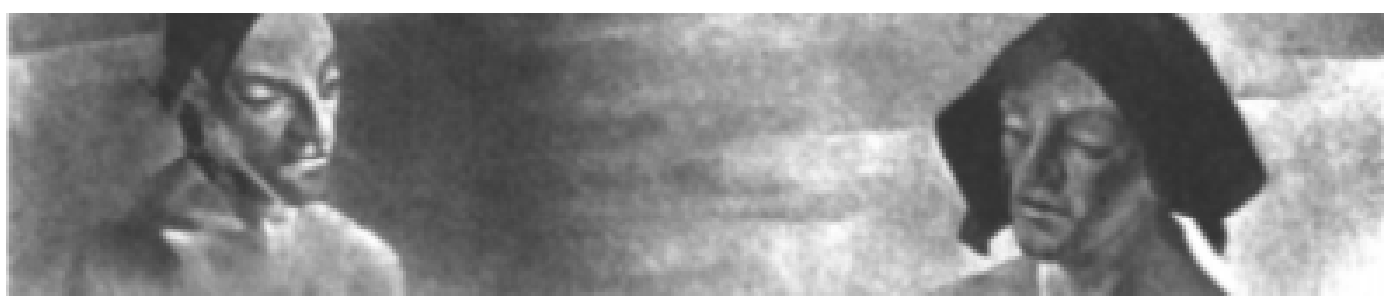


Tabela 6 - Freqüência e percentagem das justificativas para a doação de um filho ( $N=60)$.

\begin{tabular}{l|r|r|}
\hline Justificativas para a doação & G. Masc. & \multicolumn{1}{c|}{ G. Fem. } \\
\hline Em casos extremos (prostituição, uso de drogas, violência) & $(12) 40 \%$ & $(14) 47 \%$ \\
\hline Falta de condições financeiras & $(12) 40 \%$ & (9) $30 \%$ \\
\hline Não se justifica & $(10) 33 \%$ & $(10) 33 \%$ \\
\hline Risco de vida por parte dos pais biológicos & $(9) 30 \%$ & $(11) 37 \%$ \\
\hline Imaturidade dos pais & $(2) 7 \%$ & ---------
\end{tabular}

Como podemos observar, tanto para os homens (40\%) como para as mulheres (47\%), a doação só deve ocorrer em casos extremos. Isso foi seguido da falta de condições financeiras do doador, com $40 \%$ para os homens e 30\% para as mulheres. O item não se justifica obteve 33\% para ambos os sexos, ficando risco de vida por parte dos pais biológicos com 30\% para os homens e 37\% para as mulheres. A imaturidade dos pais foi percebida apenas pelos homens, com uma percentagem de $7 \%$.

Finalmente, na tabela 7 encontramos os resultados acerca do direito do doador de reencontrar o filho. o filho $(\mathrm{N}=60)$.

\begin{tabular}{|l|r|r|}
\hline Direito ao reencontro entre doador e seu filho & G. Masc. & G. Fem. \\
\hline É um direito da criança conhecer seus pais biológicos & $(14) 47 \%$ & $(16) 53 \%$ \\
\hline Depende do contexto & $(11) 37 \%$ & $(15) 50 \%$ \\
\hline Deve-se permitir o reencontro & (7) $23 \%$ & (4) $13 \%$ \\
\hline Deve-se atender os interesses dos pais adotivos & $(7) 23 \%$ & (3) $10 \%$ \\
\hline Só se justifica em casos extremos & & \\
(transplante, doenças genéticas etc.) & (5) $17 \%$ & (3) $10 \%$ \\
\hline Não se deve permitir o reencontro & --------- & (3) $10 \%$ \\
\hline
\end{tabular}

Na percepção dos respondentes, encontramos $47 \%$ dos homens e $53 \%$ das mulheres, concordando que é direito da criança conhecer seus pais biológicos. Isso foi seguido de depende do contexto para $37 \%$ dos homens e $50 \%$ das mulheres. No item deve-se permitir o reencontro, observamos os homens (23\%) mais favoráveis do que as mulheres (13\%). No que se refere a atender os interesses dos pais adotivos, deparamo-nos com uma percentagem de $23 \%$ para os homens e $10 \%$ para as mulheres. Para $17 \%$ dos homens e $10 \%$ das mulheres, só é justificado o encontro em casos extremos, como doenças, transplantes etc., e apenas $10 \%$ do grupo feminino não concorda com o reencontro.

\section{Discussão dos Resultados}

Ao analisarmos a tabela 1, encontramos que os sujeitos percebem as pessoas doadoras como incapazes de criar o filho devido à situação financeira, à imaturidade e à irresponsabilidade, lançando mão, portanto, da última alternativa para a sobrevivência da criança, que é a doação. Estudos como os de Giberti, Gore e Taborna (2001), Hartman (1994), Gonzales e Albornoz (1990), mostram que grande parte das mulheres que doam seus filhos são adolescentes de classe social desprivilegiada. Esta constatação talvez explique os resultados encontrados.

Nos dados apresentados na tabela 2 sobre os motivos que levam à doação de um filho, podemos constatar a contradição e a ambivalência dos respondentes, uma vez que assinalaram que o motivo seria achar que outra pessoa cuidará melhor do seu filho e, ao mesmo tempo, os homens assinalaram que é por falta de preocupação com o filho, sendo este resultado significativo. As mulheres, por sua vez, assinalaram o excesso de egoísmo das pessoas que entregam os filhos para adoção. Os demais resultados foram semelhantes para os dois sexos e confirmam o que foi visto na tabela 1 ao atribuírem a doação à falta de condições financeiras, ignorância e imaturidade dos doadores, especialmente a mãe. ponto positivo bastante assinalado. Isto nos remete à história da adoção, onde se observa que era praticado o 
infanticídio como forma de os pais se livrarem das crianças indesejáveis, sendo este um dos fatores mais relevantes para a criação dos orfanatos, "o mal menor", segundo Vargas (1996), Weber (1998) e Marcílio (1998). Relacionados a esse item, temos as categorias oferecer cuidados e condições de sobrevivência à criança e não foi praticado um aborto. Ainda encontramos o item fazer outras pessoas felizes como ponto positivo, uma vez que a doação daria possibilidade para pessoas que não podem gerar seus próprios filhos constituírem suas famílias.

A tabela 4 apresenta os resultados acerca das repercussões da doação na vida do doador. As categorias que se destacaram foram sentimentos de perda/vazio, culpa e remorso, desespero e amargura, preocupação com o futuro do filho, arrependimento e dúvidas sobre seu ato. Estudos realizados com pais doadores (Deykin, Campbel e Patt 1988, apud Hartman, 1994) encontraram respostas similares às contidas na nossa pesquisa, como sentimento de perda, vazio e efeitos negativos em suas vidas. Brodzinsky (1990, citado em Hartman, 1994), ao entrevistar pais doadores, verificou a existência de preocupação com o futuro do filho, o que também ocorreu na percepção de nossos respondentes. Chama a atenção o item alívio por se livrar da responsabilidade, que foi assinalado apenas por algumas mulheres, o que está de acordo com o que foi assinalado quanto ao excesso de egoísmo por parte do doador. Isto parece indicar uma severidade maior no julgamento feito pelas mulheres, talvez abalizadas na crença de que o amor materno é inato e no ditado que diz que "mãe que é mãe não abandona sua cria".

A tabela 5 focalizou as repercussões da doação na vida do filho, na qual se verifica que a maioria dos sujeitos assinalou que elas vão depender da idade da criança. Em menor freqüência apareceram as respostas sentimentos de vazio e rejeição, tristeza e baixa auto-estima, gerando, por sua vez, desajustamento emocional. Uma minoria assinalou que a criança entregue para adoção fica impossibilitada de ser uma pessoa ajustada e feliz. Embora a presença dos sentimentos citados tenha sido reconhecida por estudiosos da adoção (Eliacheff, 1995; Hartman, 1994; Maldonado, 1994; Schettini, 1995), é possível que, com a intervenção precoce e um ambiente familiar propício, aliado a uma condução adequada do processo de adoção, tudo isso favoreça o bom ajustamento da criança adotada. Para Berthoud (1997), existem possibilidades de a criança adotiva desenvolver a capacidade de apego, semelhante ao que ocorre com o filho biológico. Para a autora, a idade da criança e a disponibilidade, principalmente da mãe adotiva, para desenvolver relações afetivas são elementos essenciais para a superação das fases críticas da adaptação da criança na família adotiva. Isto confirma a percepção de que há possibilidade de essa criança ser feliz e ajustada quanto mais cedo for sua inserção no lar adotivo, conforme foi assinalado pelos sujeitos no item depende da idade da criança. É animador constatar que os respondentes acreditam na possibilidade de a criança adotiva ser um indivíduo feliz, uma vez que a minoria assinalou que ela fica impossibilitada de sê-lo .

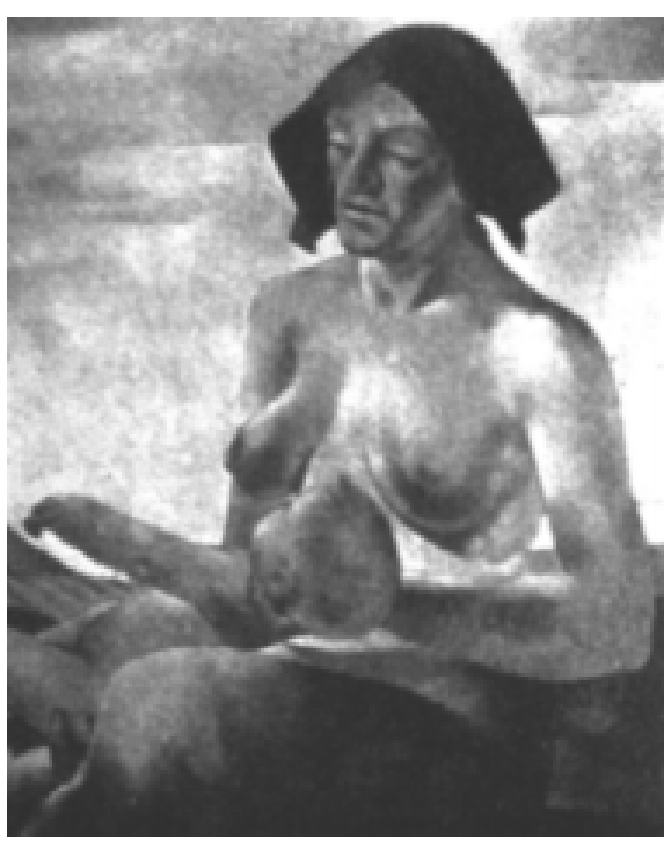

Ao analisarmos a tabela 1 encontramos que os sujeitos percebem as pessoas doadoras como incapazes de criar o filho devido à situação financeira, à imaturidade e à irresponsabilidade, lançando mão, portanto, da última alternativa para a sobrevivência da criança, que é a doação.

De acordo com os resultados da tabela 6, que listou as justificativas para a doação de um filho, observamos que os sujeitos assinalaram que a doação só é justificada em casos extremos, por falta de condições financeiras e em casos de risco de vida por parte dos pais biológicos. Houve uma parcela de respondentes que não acha a doação justificável. Apenas o grupo masculino assinalou o item imaturidade dos pais como uma justificativa para a doação, assim mesmo em um percentual inferior.

Finalmente, acerca do direito ao reencontro do doador com o filho (ver tabela 7), vimos que a maioria dos sujeitos concorda que é um direito da criança conhecer seus pais biológicos, seguida da resposta depende do contexto. Uma minoria acredita que o reencontro deve atender ao interesse dos pais adotivos e que só deveria ocorrer em casos extremos. Novamente as mulheres mostram-se mais severas ao indicarem que não se deve permitir o reencontro.

Sem dúvida, esses resultados mostram maior abertura na percepção dos respondentes, acompanhando, talvez, a evolução dos tempos, como também a maior divulgação que o tema adoção vem usufruindo junto ao público em geral. 
O assunto reencontro ainda é um tabu que precisa ser enfrentado pelos pais adotivos, os quais temem perder o amor do filho, caso o reencontro venha a se concretizar. No entanto, estudos têm indicado que, se os pais adotivos encaram com naturalidade o desejo dos filhos irem em busca de sua origem e até os auxiliam nessa busca, isto é um fator de maior proximidade entre eles (Hartman, 1994).

Os pais biológicos também desejam ser encontrados. Um exemplo disso é que, no estado de Michigan, em 1980, apesar da grande pressão social para que o fato não ocorresse, foi facultado o direito de as mães biológicas deixarem informações para seus filhos doados, e os mesmos, ao atingirem a maioridade, terem direito, caso queiram, de reencontrá-las. Desde então, $98 \%$ das mães deixam informações (Hartman, op. cit.).

Ao analisarmos a tabela 7, parece-nos que há uma predisposição a romper um pouco o silêncio que tem prevalecido acerca do tema adoção ao não se negar a presença de alguém que gerou o filho que outros não puderam ter como alguém participativo desse processo. Concordamos com a posição de Eliacheff (1995) e Vargas (1998), que acreditam ser necessário um programa de preparação para todos os participantes desse evento: os pais biológicos, especialmente a mãe biológica, o bebê a ser adotado e os pais postulantes à adoção.

\section{Conclusão}

O presente trabalho teve como objetivo investigar como as pessoas, de maneira geral, percebem o fato de se entregar um filho para adoção e o doador especialmente a mãe. Concluímos que parece estar havendo uma maior abertura para com o tema da doação, embora ainda permeado por contradições e ambivalências. Notamos maior severidade por parte das mulheres para com o doador ao considerá-lo egoísta e não concordarem com seu reencontro com o filho doado, embora isto tenha ocorrido por parte de uma minoria. Os homens, por sua vez, acharam que o motivo que leva uma pessoa a doar um filho é a falta de preocupação com o mesmo, demonstrando contradição ao indicarem também que essa pessoa doaria o filho por considerar que outra cuidaria melhor dele. $\mathrm{Na}$ nossa opinião, isto não deixa de revelar uma preocupação para com o bem-estar do filho.

Reconhecemos limitações na nossa pesquisa ao não controlarmos variáveis como nível sócioeconômico, escolaridade, idade dos sujeitos. Salientamos que nosso interesse foi realizar um levantamento inicial, enfocando apenas algumas variáveis mais estamos conscientes da necessidade de aprofundamento do assunto. Recomendamos, portanto, a continuação de pesquisas que possam acrescentar outras variáveis ou aprofundar as que foram estudadas como forma de conhecermos cada vez mais esse tema complexo e fascinante.

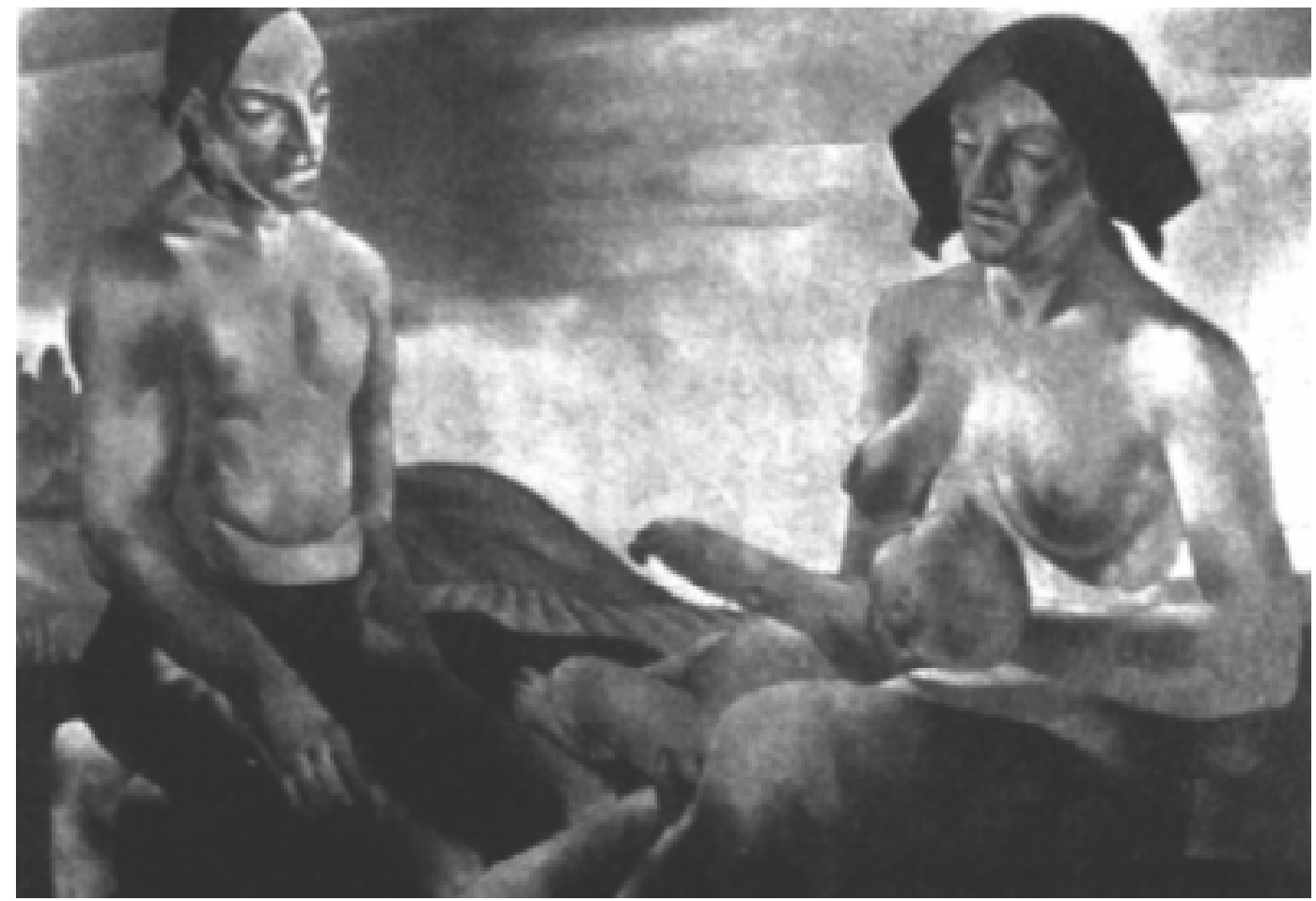


Berthoud, C. (1997). Filhos do Coração. São Paulo: Cabral Editora Universitária.

Bonnet, C. (1991).O Abandono ao Nascer, uma Outra Perspectiva. Tradução de Maria Antonieta Pisano Motta (on line). Adoção Páginas Brasileiras. Disponível: omotto@mcharm.com.br.

Eliacheff,C. (1995).Corpos que Gritam. São Paulo: Ática.

Freston, Y. M. \& Freston, P. (1994) AMãe Biológica em Casos de Adoção: um Perfil da Pobreza e do Abandono. In F. Freire (Org.). Abandono e adoção II. Curitiba: Terra dos Homens, pp. 81-94.

Giberti, E., Gore, S. C., Taborda, B. (2001). Mães Excluídas. In F. Freire (Org.). Abandono e Adoção, Contribuições para uma Cultura da Adoção III. Curitiba, Terra dos Homens, pp. 177-186.

Gonzales, L., Albornoz, C. (1990) Niños Entregados en Adoptión: Factores Desencadenantes. Rev. Child. Pediatr. 61 (1), pp.25-28.

Hartman, A. (1994). Segredosnaadoçáo. In E. Imber-Black (Org.). Segredos na Família e na Terapia Familiar. Porto Alegre: Artes Médicas, pp. 94112
Leão, S. C. (1990). Infância, Latência e Adolescência. Rio de Janeiro: Imago. Marcilio, M. L. (1998).História Social da Criança Abandonada. São Paulo: Hucitec.

Maldonado, M. T. (1995).Os Caminhos do Coração, Pais e Filhos Adotivos. São Paulo: Saraiva, $2^{a}$ edição.

Santos, L. S. (2001). Mulheres que Entregam seus Filhos para Adoção, os Vários Lados dessa História. In F. Freire (Org.). Abandono e Adoção, Contribuições para uma Cultura da Adoção III. Curitiba: Terra dos Homens, pp. 189-196.

Schettini, L. F. (1995).Compreendendo os Filhos Adotivos. Recife: Bagaço.

Vargas, M. M. (1998). Adoção Tardia, da Familia Sonhada à Família Possível. São Paulo: Casa do Psicólogo.

Weber, L. M. D. (1998). Laços de Ternura: Pesquisas e Histórias de Adoção. Curitiba: Santa Mônica.
Referências bibliográficas 